Саввина О.В.

\title{
Мультипликационный сериал как художественный продукт (на примере мультсериалов «Смешарики» и «Маша и медведь»)
}

Аннотация: В статье рассматривается основная идея (концепция), современных популярных российских мультипликационных сериалов на примере мультсериалов "Смешарики» и «Маша и медведъ», а также этические ценности, лежащие в её основе. В последние десятилетия мультсериалы, базирующиеся на таких этических ценностях как доброта, дружба, семъя и т.д. набирают популярность. Описание общих принципов успешного мультсериала составляет цель исследования. Мультсериал - художественный продукт, поэтому очень важна художественная составляющая мультсериала и способы продвижения сериала на внутренний и международный рынок. В статье делается анализ как самих мультипликационных сериалов - их сюжета, фабулы, основной идеи, средств выражения, графики и т.д. так и интервью с создателями и авторами идеи, обращается внимание на способы раскрутки бренда. Автор приходит к выводу, в настоящее время основная идея (концепция) мультипликационного сериала - залог успеха продукта на российском и международном рынке. Тем не менее, популярный сериал не обходится без привлечения авторитетных профессионалов в индустрии, обеспечивающих качественное доведение идеи сериала до потребителя, которое способно затронуть чувства аудитории, и грамотного продвижения на первых этапах раскрутки бренда.

Ключевъе слова: Мультипликационный сериал, художественный продукт, ценности, анимация, продвижение, государственная поддержка, положительный герой, отрицательный герой, концепция мультипликационного сериала, традиционные ценности.

Review: The article analyses the core idea (concept) of the Russian modern popular animated series (the examples of "Smeshariki" and "Masha and the Bear") and its ethical values. In recent decades animated series that are based on such ethical values as kindness, friendshi, family and so on are growing in popularity. The purpose of the present research is to describe general principles of making successful animated series. Animated series are artistic products that is why an artistic component is very important in conveying the idea to the audience as well as marketing and promotion of animated series on domestic and international markets. The author of the article analyses the basic idea of animated series and episodes and their stories, plots, graphics and etc. as well as interviews with the authors of the ideas and promoters. The study also pays attention to the marketing and branding. The author comes to the conclusion that nowadays the good basic idea (concept) of animated series is necessary to succeed on the market. However, there are no popular animated series without well-known professionals in the industry providing quality embodiment of the basic idea and affecting feelings of the audience. Good promotion at the first stages of promoting the brand is also very important.

Keywords: Villain, hero, government support, promotion, animation, values, artistic product, animated series, concept of animated series, traditional values.

\section{Введение.}

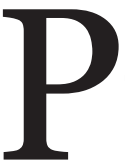
оссийская анимация за последние два десятилетия всё более набирает силы, становится популярной не только в России, но и за рубежом. Мультипликационные сериалы получают финансовую поддержку государства, транслируются на за- рубежных каналах, персонажей анимационных сериалов можно встретить в детских книгах, компьютерных играх, на упаковках продуктов питания и других товарах, ориентированных на детскую аудиторию. Тем не менее, в научных журналах очень мало информации, посвящённой как российским, так и зарубежным анимационным сериалам: созданию кон- 
цепции и сюжетной линии, производству и раскрутке сериала. В Интернете на профессиональных ресурсах и тематических порталах существует лишь разрозненная информация, часто касающаяся маркетинга, или интервью с авторами успешных анимационных сериалов в свободной форме. Практически невозможно найти разбор идеи (концепции) мультипликационного сериала.

В данной статье делается попытка описания основной идеи (концепции) мультипликационного сериала с этической точки зрения, т.е. анализ ценностей, изначально заложенных авторами идеи. Предполагается, что ценности и идеалы, заложенные в концепцию сериала, во многом делают его привлекательным для аудитории.

Сейчас российские анимационные сериалы успешно конкурируют с зарубежными на отечественном рынке и за его пределами. Для успеха необходима хорошая основная идея, но этого мало: необходимы средства выражения, позволяющие передать эту идею, донести её до потребителя (как ребёнка, так и взрослого). Поэтому рассмотрение российского сериала как художественного продукта будет неполным без рассмотрения «приёмов» мультипликаторов, к которым они прибегают, чтобы сделать мультфильм «живым», а героев запоминающимися, характерными. Для того, чтобы понять, что выгодно отличает российский анимационный сериал последних лет, необходимо рассмотреть популярные проекты. Для анализа преимущественно использованы мультсериалы «Смешарики» и «Маша и медведь».

Для анимационного сериала, как и для всякого художественного продукта, важно продвижение на рынок, поиск финансирования, в том числе и фендрейзинг: на эту составляющую производства тоже нельзя не обратить внимания. Продвижение мультсериала на начальных этапах будет также проанализировано в настоящей статье.

\section{Анимационный сериал как произведение искусства. Концепция сериала.}

Согласно теории о 4P маркетинга (product, price, place, promotion) маркетинг начинается с продукта, а анимационный продукт - с идеи, концепции. Анимационный сериал - это не только художественный продукт, но и произведение искусства, в котором, как в литера- турном произведении, очень важны идея произведения, сюжет, фабула, а также средства изображения. Наиболее популярные проекты последних лет - это «Смешарики» студии «Петербург» (продюсерский центр «Рики») и «Маша и медведь» анимационной студии «Анимаккорд». Их концепции и стоит рассмотреть в первую очередь.

«Смешарики» - мультипликационный сериал, рассчитанный на детскую аудиторию 3-12 лет и, как указано на официальном сайте сериала, их родителей. Герои сериала - шарообразные милые зверушки, живущие в своей долине. Вот основные герои: Крош (кролик), Ёжик (ёж), Нюша (свинья), Совунья (сова), Кар-Карыч (ворон), Копатыч (медведь), Бараш (баран), Пин (пингвин), Лосяш (лось). Каждый из героев имеет свой ярко выраженный характер и темперамент, обладает набором интересующих его занятий, любимых фраз. Каждая серия «Смешариков» рассказывает о новом приключении героев, имеет отдельное название и, как правило, завязка сюжета, кульминация и развязка умещаются в одну серию продолжительностью 6 - 16 минут (13-16 минут длятся серии спин-офф «Пин-код»). За всю историю сериала было всего несколько исключений, например, эпизод «Эффект бабушки» растянулся на 3 серии, а «Прививка от Кроша» из проекта «Пин-код» - на две.

Первая серия «Смешариков» «Скамейка» вышла в 2003 году, с тех пор мультсериал не только покорил российских детей и их родителей, но зарубежные страны: «Смешариков» транслируют в странах Евросоюза, США, Канаде, Великобритании, Китае и многих других странах. Как говорит продюсер сериала Илья Попов, «Смешариков» сморят в 60-70 странах, Попов не может назвать точное число, поскольку и сам перестал считать после определённого момента [1].

«Смешарики» были созданы при поддержке культурно-образовательного проекта «Мир без насилия», и мультфильм, следуя логике проекта должен нести «разумное, доброе, вечное», воспитывать толерантность и служить «профилактике экстремизма». Создатели мультсериала отказались от традиционного противостояния хороших и плохих героев, не вводя негативных персонажей. Автором идеи стала, по выражению художественного руководителя мультсериала Анатолия Прохорова, художник А. Мальгинова, сказав «а давайте снимем, что какие-то шибзики живут вместе и 
не убивают друг друга» [2]. Феноменально, но эта идея действительно выглядит новаторской для мультипликационных детских сериалов. В советских мультсериалах, воспринимающихся людьми зрелого возраста как шедевры анимации, таких как «Ну, погоди!», «Кот Леопольд» присутствуют негативные персонажи, которые, правда, зачастую раскаиваются в содеянном и не лишены привлекательных черт. Поколение 1990-х и вовсе выросло на зарубежных мультсериалах «Черепашки Ниндзя», «Сэйлор Мун» и т.д., в которых негативный персонаж стремиться разрушить мир и не подлежит исправлению. В контексте этих сериалов победа над злом может быть лишь одна - убийство негативного персонажа, таким образом, насилие предстаёт перед детьми как добро, и даже необходимость. Весь сюжет подобных мультсериалов строится на войне и противостоянии, что опять же внушает детям, что жизнь - это война, если не ты убьёшь, то тебя убьют. Подобные сюжетные линии также приучают видеть мир упрощённо: чёрное - белое, враг - друг, если ты не с нами - то против нас. А ведь мир сложнее и многограннее, да и не всё стоит оценивать как хорошее или плохое, такая шкала одномерна и редко соответствует действительности. В то же время сюжет, основанный на противостоянии, решает извечную творческую проблему сериала - создание большого количества серий: достаточно всего лишь придумать новую проделку негативного героя, чтобы герой положительный опять спас мир от разрушения. Поэтому, взявшись построить мир без насилия творческая команда «Смешариков» возложила на себя более сложные творческие задачи с точки зрения сценария и режиссуры. «В наших историях нет морали, мы очень тщательно следим, чтобы наш сериал не обладал двумя свойствами, которыми обладает плоская и по-взрослому придуманная детская культура - сюсюканьем, то есть заигрыванием с детьми, и назидательностью» [2] утверждает Анатолий Прохоров. Отсутствие морализаторства, реальные жизненные ситуации, в которые погружается ребёнок ещё с детского сада и которые существуют во взрослом коллективе - вот ядро концепции сюжетной линии «Смешариков».

Само название «СмеШАРики» происходит от «смешные шарики», соответственно неразлучным спутником серий должен стать юмор, но юмор добрый, а не чёрный. Как указано на официальном сайте «Смешарики» - это мультсериал для детей и их родителей (это положение не раз подчёркивалось в интервью продюсером сериала - Ильей Поповым и художественным руководителем - Анатолием Прохоровым). Эта установка обрекает «Смешариков» на двойное дно их юмора: буквальный, воспринимаемый детьми и более абстрактный, воспринимаемый взрослыми. Эта характеристика очень важна с точки зрения расширения целевой аудитории (т.е. маркетинга), так как включают мультики детям часто их родители, которые не против и сами посмеяться за просмотром очередной серии после тяжёлого рабочего дня.

Первое, что бросается в глаза при просмотре мультфильма - это изображение, его можно назвать основным средством выражения концепции анимационного фильма. Как выразился художник и один из соучредителей ООО «Смешарики» Салават Шайхинуров, персонажи мультфильма очень просты «их может нарисовать даже ребёнок». Они простые, добрые и милые, без слащавости и искусственности, которая часто присуща добрым персонажам. Кроме того, герои «Смешариков» - животные, которые, как правило, очень нарваться детям. «Звериная» тема - одна из ключевых в мультипликационных фильмах. Уважение к животным было присуще нашим предкам, поклонявшихся тотемам, или священным животным, своего племени [3]. Люди жили бок о бок с животными на протяжении всей своей истории, в лесах и саваннах, в оседлых поселениях и племенах кочевников. Животные присутствуют в сказках и легендах, которые с удовольствием слушают дети. Возможно, симбиоз человека и животных находится у нас в подсознании, является архетипом нашей психики, и сейчас, в городах детям порой не хватает общения с животными. Именно поэтому «звериная» тема возрождается в мультипликационных фильмах вновь и вновь. Тема природы вообще очень ярко отображена в «Смешариках», которые живут в долине на лоне природы.

Немаловажны также характеры персонажей. Личность и темперамент каждого из героев довольно ярко прорисованы. «Каждый герой представляет определенный психологический тип и возраст. Их взаимодействие позволяет продемонстрировать ребенку основной спектр человеческих отношений, помочь ему адаптироваться в окружающем мире» [2]. Кроме того, поскольку основных персонажей девять - в одном из них можно 
угадать себя или своего хорошего знакомого. Узнаваемость ситуаций и персонажей - один из залогов успеха на экране.

Следующей интересной чертой мультсериала является использование сюжетов и идей известных и узнаваемых кинопроектов, фраз из известных фильмов, которые обычно заложены во «второе дно» юмора мультфильма. Подобные приёмы использованы в сериях «Танцор диско», «Марафонец», «Бутерброд» и др. Такая логика построения сюжета также работает на узнаваемость ситуаций и персонажей, привлекает зрителей.

Следующий популярный российский сериал - «Маша и медведь», который выходит с начала 2009 года и уже успел завоевать не только российскую аудиторию, но многие зарубежные страны. За почти семь лет существования сериала вышло 57 серий и 2 спин-оффа («Машины сказки» и «Машкины страшилки»). Мультфильм с самого начала выходит в формате 3D. Герои мультсериала - маленькая озорница Маша и Медведь, бывший цирковой артист, который живет в лесу в своём доме. Маша периодически заходит в гости к медведю, где они вместе играют, ухаживают за растениями на огороде медведя, работают по хозяйству - варят варенье и т.д. Конечно же, Маша не обходится без проделок и шалостей, зачастую искренне пытаясь помочь Медведю.

Прототипом Маши была реальная девочка - озорница, которую автор идеи - Олег Кузовцов встретил в 1996 году [4]. Малышка никому на пляже не давала спокойно отдохнуть, включая собственных родителей. «Маша и медведь», также как и «Смешарики» - мультфильм для всей семьи, с «двойным дном». Прообразом Медведя является «воскресный папа», родитель, жаждущий отдохнуть в выходной, полежать, половить рыбу или посмотреть телевизор. Но увы, подобный отдых не входит в планы его чада. Оба персонажа добры, они дороги друг другу, всегда пытаются помочь друг другу. Можно сказать, что в сериале всё время присутствуют семейные ценности, родительская любовь. Маша живёт в сельском доме недалеко от маленькой железнодорожной станции вблизи леса.

В отличие от «Смешариков» «Маша и медведь» гораздо более реалистичны с точки зрения изображения. Единственное «но», это, пожалуй, излишне большая голова Маши. Стук колёс поезда, ручей, бытовые предметы и посуда очень реалистичны, объёмны, такое ощущение, что можно протянуть руку в экран и взять сковородку или другую утварь в доме Медведя. В мультипликационном сериале очень много природы и животных. Животные в «Маше и Медведе» - отдельная тема. Они не антропоморфны как во многих мультфильмах, не разговаривают на человеческом языке, но при этом они всё понимают, активно участвуют в проделках Маши, общаются с ней. Такая реалистичность изображения в совокупности с «интеллектуальностью» лесных зверей, золотой рыбкой в пруду и чудесами Деда Мороза, который также встречаются в мультипликационном сериале, создаёт ощущение присутствия сказки в нашей обыденной жизни. Именно так дети младшего возраста чувствуют мир, для них нет границы между сказкой и былью, в любой момент может свершиться чудо, а животные - они такие же, как мы, просто по-человечески не разговаривают. Поэтому «Маша и медведь» - мультфильм, который понимает детей, их мироощущение. Такая двойная канва мультипликационного сериала, с одной стороны - детское миропонимание, а с другой - взрослая проблема «как справиться со своим любимым чадом» делает его уникальным, живым, близким для детей и их родителей. Характеры Маши и медведя - это типажи родителя и ребёнкаозорника, они не уникальны, но каждый родитель и ребёнок могут увидеть в этих героях себя. Это обеспечивает не только симпатию зрителя, но и узнаваемость персонажей. В «Маше и медведе» очень много из «отсылок» к советским фильмам и песням (используются фразы, музыка, слова из песен). Отсылки в «Маше и медведе» пробуждают в памяти реалии обычной советской и в последствии российской жизни, а, следовательно, делают сериал ещё более реалистичным и близким к нашей жизни. Взрослые как будто «видят кадры» из собственного детства, вспоминая свои детские шалости и своё детство, и лучше понимая своих детей, даже под тяжёлым грузом взрослых проблем и задач.

Отдельно следует отметить, что «Маша и медведь» очень «русский» мультсериал. Он о российской жизни и для российского зрителя, несмотря на то, что завоевал популярность и за рубежом - там наш лес, наша железнодорожная станция, наши животные, утварь и холодильник в доме Медведя - это утварь, которую поколение 1980-х и 1990-х видело в сельских домах своих бабушек и дедушек. Именно у этого поколения сейчас дети дошкольники 
- основная целевая аудитория мультсериала. И, в завершение, «Маша и медведь» - название известной всем с детства русской народной сказки.

В настоящий момент в России кроме упомянутых проектов существуют очень интересные анимационные сериалы. Среди наиболее удачных «Лунтик и его друзья», «Барбоскины» студии «Мельница», «Гора самоцветов» студии «Пилот», «Фиксики», «Белка и стрелка» группы компаний «Рики» и другие. Все эти мультфильмы не содержат злых персонажей. Многие из них - познавательные. Например, в сериале «Лунтик и его друзья», ориентированного на самую младшую возрастную категорию, проясняются элементарные понятия, объясняется смысл крылатых выражений, дети знакомятся с миром насекомых и животных, которых они, возможно ещё не встречали (кузнечик, лягушка, жук и т.д.). В сериале «Фиксики» в доступной для детей форме освещаются принципы работы той или иной техники, законы физики. Спин-офф «Пин код» с героями «Смешариков» рассказывает о научных законах и теориях в области естественных наук.

Особняком стоит мультипликационный сериал «Гора самоцветов», каждая серия которого - сказка одного из народов России. В начале каждой серии кратко и не навязчиво рассказывается о народе, из чьего фольклора взята сказка, его обычаях и традициях. Серии «Горы самоцветов» сделаны в разных анимационных стилях. Данный сериал имеет ярко выраженную культурную и образовательную компоненту, направлен на воспитание патриотизма и толерантности. Дети, как правило, с удовольствием смотрят «Гору», ведь сказка это мудрость народа, иносказание, в котором скрыт более глубокий смысл [5]. Отсюда и название сериала: каждая сказка, как драгоценный камень (а может идея, которую выражает сказка). Этот анимационный сериал получил не одну награду: Национальная премия в области кинематографии «Золотой Орел» за 2005 г. в категории «Лучший анимационный фильм», Спецприз жюри Международного фестиваля анимационных фильмов «КРОК» (2005) и ряд других. Сериал выходил при финансовой государственной поддержке министерства культуры Российской Федерации.

В последнее время среди российских анимационных сериалов очень много 3D проектов («Пин код», «Маша и медведь», «Фиксики», «Барбоскины», «Белка и стрелка». «Тишка» и др.). Следует заметить, что эта идея пришла к нам с Запада, пионером в области компьютерной графики в анимации является американская компания PIXAR. Применение компьютерных технологий сейчас является общемировой тенденцией и российская анимация здесь не исключение.

Среди российских мультсериалов немало в той или иной степени антропоморфных персонажей - животных и неодушевлённых предметов - чаще всего поездов, машин («Барбоскины», «Белка и стрелка», «Паровозик Тишка» и др.).

\section{От стартапа к бренду: продвижение мультипликационных сериалов (на примере «Смешарики», «Маша и медведь», «Гора самоцветов»).}

Мультипликационный сериал начинается с идеи, но осуществить её не просто. Производство мультипликационных фильмов процесс затратный, требующий привлечения специалистов из разных областей - художников, режиссеров, сценаристов, продюсеров, специалистов в области компьютерных технологий и других. Коллективу необходимо помещение для работы и техническая база. Идея мультфильма «Маша и медведь» родилась в 1996 году, а первая серия вышла в свет лишь в 2009-м. Чтобы сложить все части в единое целое и создать хороший продукт часто прибегают к копродукции [6]. При создании первых двух серий «Маша и медведь» «Анимаккорд» заказывала анимацию и рендеринг (визуализация модели на основе компьютерной программы). Пилотную серию «Маши и медведя» выполнила компания студия A-VFX, и на неё ушло около восьми месяцев. Когда у команды «Смешариков» - Салавата Шайхинурова, Ильи Попова и других появилась идея мультфильма, они обратились к опытному специалисту в области мультипликации - Анатолию Прохорову.

Проекту также необходимо финансирование, особенно на первых этапах, когда персонажи ещё не узнаваемы. Фандрейзинг - один из способов получить средства, необходимые для старта проекта. «Гора самоцветов» выходила при поддержке Федерального агентства по культуре и кинематографии, «Смешарики» - при поддержке Минкультуры РФ. В России финансированием мультипликационных сериалов на начальном этапе в основном занимаются государственные структуры. Под- 
держка художественных и научных проектов традиционна для России. Подобная практика сложилась ещё в СССР, когда государство выделяло финансирование на перспективные проекты отдельным государственным институтам и учреждениям культуры, а в современных реалиях государство выделяет средства перспективным проектам, отвечающим концепции государственной культурной политики. Аниамационные проекты не являются приоритетными с точки зрения финансирования. В 2014 году при поддержке Министерства культуры РФ было завершено 155 анимационных фильмов, запущено в производство 69 анимационных проектов, в том числе 44 детских и 25 авторских фильмов, в то время как в этом же году 242 неигровых и 71 игровой фильм получили поддержку, 383 неигровых видеофильма по 19 тематикам и 96 игровых были выпущены [7]. Объём финансирования производства национальных анимационных фильмов составил в 2014 году 15\% от средств, выделяемых на кинематографию. Такие объёмы финансирования - это общемировая тенденция: европейские фонды, а также государства спонсируют анимационные фильмы в значительно меньшей степени, нежели кинематографию. Европейский фонд поддержки кино «Eurimages» и вовсе не спонсировал анимационное кино до 2012 года, и сейчас поддержка этого сегмента не превышает 10-15\% [6].

Ещё одним источником поддержки начинающих проектов могут стать анимационные студии, уже добившиеся успеха. «Анимаккорд» и «Рики» готовы к сотрудничеству и готовы инвестировать в перспективные по их оценкам проекты. На сайте «Анимаккорд» указано, что компания будет сотрудничать только с оригинальными проектами, а не переделками западных идей и пародиями. Это свидетельствует о том, что хорошие идеи нынче востребованы.

\section{Перспективы развития бренда мультипликационного сериала.}

Первый сезон «Маши и медведя» был продан более чем в 100 стран [8]. На фестивале в Каннах было представлено не мало российских анимационных фильмов, включая сериалы («Маша и медведь» - студия «Анимаккорд», российско-испанский проект, созданный в копродукции с Wizart TV Series - московское подразделение Wizart
Animation с испанскими компаниями Somuga и Dibulitoon, «Алиса знает, что делать!» Bazelevs Distribution, «Малышарики», «Смешарики 3D. Новые приключения», «ПинКод» - продюсерский центр «Рики», «Лунтик и его друзья» - студия «Мельница», «Паровозик Тишка» - АА Студио, «Летающие звери» - Студия «Да» и другие) [8].

Тем не менее, телевизионный эфир и выпуск мультсериала на электронных носителях (DVD) не приносит больших денег и вряд сможет покрыть расходы [1]. Поэтому бренд, в отличие от мультсериала может стать хорошим источником дохода. Анимационные студии и продюсерские центры сотрудничают с компаниями - производителями игрушек, продуктов питания, производителями книг и полиграфической продукции, канцелярских товаров, и, конечно же - компьютерных игр. Одна из особенностей современного рынка заключается в тесной связи анимационного кино и компьютерных игр. По мотивам «Смешариков» была выпущена компьютерная игра «Шарарам» и другие игры, «Маша и медведь» тоже легли в основу целого ряда компьютерных продуктов и обучающих детских компьютеров и игрушек. Некоторые анимационные студии сами берутся за производство игрушек, как это случилось со «Смешариками», когда руководству студии «Петербург» не понравились предложенные продукты. Создатель «Лунтик и его друзья» Константин Бронзит также остался не доволен игрушкой Лунтика, предложенной китайскими производителями. Сейчас герои мультипликационных сериалов заполняют прилавки детских сетевых супермаркетов, таких как «Дочки и сыночки» и «Кораблик». Их можно встретить на тетрадках и дневниках, книжках, в качестве игрушек, на детской посуде, шариках, самокатах, велосипедах и много ещё где. Производители этих товаров - партнёры анимационных студий, обладателей прав на персонажи мультипликационных сериалов. Как правило, анимационная студия имеет лицензионную программу, в соответствии с которой производитель-партнёр может использовать бренд студии.

Ещё одним выгодным направлением и перспективным с точки зрения экспансии российской культуры является сотрудничество с зарубежными и международными каналами и анимационными студиями. В 2014 году на Европейском анимационном рынке MIFA в рамках стенда RUSSIAN CINEMA. 
ANIMATION прошло более 330 индивидуальных встреч и переговоров. По заявлению генерального директора «Анимаккорд» Дмитрия Ловейко сумма сделки на 2015 год составит около 10 миллионов рублей [9]. В рамках того же мероприятия продюсерский центр РИКИ провел успешные переговоры по вопросам дистрибуции с компаниями Pikkuli, Timo Lampinen Production, Anima Vitae, Favex, Undo из Финляндии, Motion Picures, GoldBee, Dot4 из Испании, Artha Animation, 7 Mantle Studios, Yuva Animation studios, Motion Makers Studios, Barking Cow Media Group, Anand Gurnani Media из Индии, а также компаниями из Италии, Колумбии и Туниса [9]. Международное сотрудничество - не только выгодно с позиции бизнеса, но позволяет рекламировать российскую культуру за рубежом, а также позиционировать и продвигать российский художественный продукт на международной арене.

Итак, российские мультипликационные сериалы - перспективный художественный продукт. Он охватывают большую целевую аудиторию, популярен в России и за рубежом. Кроме того, анимационные сериалы несут большой образовательный потенциал: известные бренды работают над обучающими сериями, посвящёнными науке, правилам дорожного движения, этикету и т.д.; дети дошкольники и младшего школьного возраста могут с большим удовольствием учиться с помощью пособий с героями из любимых мультипликационных сериалов. Альбомы для рисования, наборы для творчества приобщают ребёнка к искусству и, тем самым, помогают ему развиваться [12]. Несомненно, тема анимационных сериалов нуждается в более детальной проработке и междисциплинарном подходе. Концепции сериалов нуждаются в анализе с точки зрения философских направлений, в особенности этики и эстетики; психологии личности и детской психологии; образования и педагогики. Специалистам в области менеджмента и маркетинга следует проанализировать анимационные сериалы как рыночный продукт, нуждающийся в оценке качества и продвижении на отечественный и зарубежный рынок. Государственным структурам анимационные сериалы могут быть интересны как элемент культурной политики и политики в сфере образования.

\section{Библиография:}

1. Терещенко М. Илья Попов: «Мне нравится делать то, что в России считается невозможным». / Интервью с И. Поповым. Режим доступа: http://www.kino-teatr.ru/kino/person/322/ (22.06.2015).

2. Первозванский М. Живут вместе и не убивают друг друга. / Интервью с А. Прохоровым. Режим доступа: http://www.naslednick.ru/archive/rubric/rubric_226.html (22.06.2015).

3. Леви-Стросс К. Тотемизм сегодня. / Библиотека Гумер. Режим доступа: http://www.gumer.info/bibliotek_ Buks/Culture/Lev-Str/04.php (22.06.2015).

4. Олег Кузовков. Художественный руководитель студии Анимаккорд. /Портал «Мир 3D», интервью с О. Кузовковым. Режим доступа: http://www.mir3d.ru/person/586/

5. Пропп В. Исторические корни волшебной сказки. / Библиотека Гумер. Режим доступа: http://www.gumer. info/bibliotek_Buks/Linguist/Propp_2/index.php (Дата обращения: 29.06.2015).

6. Хангильдиева И.Г. Традиционные формы в нетрадиционном контексте: аренда и копродукция в сфере культуры и искусства (материалы курса «Предпринимательство в культуре»).

7. Отчёт департамента кинематографии за 2014 год Министерства культуры РФ. / Режим доступа:

8. http://mkrf.ru/upload/mkrf/mkdocs2015/Отчет.\%20Департамент\%20кинематографии.pdf

9. Фонд кино представит рекордное количество российских проектов на кинорынке в Каннах. - По материалам пресс-службы Russian Cinema/ Портал CINEMOTION. Режим доступа:

10. http://www.cinemotionlab.com/novosti/01877-fond_kino_predstavit_rekordnoe_kolichestvo_rossiyskih_ proektov_na_kinorynke_v_kannah/ (23.06.2015).

11. Новые анимационные проекты из России были представлены на крупнейшем анимационном кинорынке Европы. / в разделе «Новости» от 14.06.2014 на официальном сайте Социальной и экономической поддержки отечественной кинематографии. Режим доступа: http://www.fond-kino.ru/ news/6/545/ (23.06.2015).

12. Мартьянова Г.Ю., Ильина А.А. Потенциал арттерапии в системе коррекционной помощи дошкольнику // Психолог. - 2015. - 1. - С. 94 - 118. DOI: 10.7256/2409-8701.2015.1.13601. URL: http://www.e-notabene.ru/ psp/article_13601.html 


\section{References (transliterated):}

1. Tereshchenko M. Il'ya Popov: «Mne nravitsya delat' to, chto v Rossii schitaetsya nevozmozhnym». / Interv'yu s I. Popovym. Rezhim dostupa: http://www.kino-teatr.ru/kino/person/322/ (22.06.2015).

2. Pervozvanskii M. Zhivut vmeste i ne ubivayut drug druga. / Interv'yu s A. Prokhorovym. Rezhim dostupa: http://www.naslednick.ru/archive/rubric/rubric_226.html (22.06.2015).

3. Levi-Stross K. Totemizm segodnya. / Biblioteka Gumer. Rezhim dostupa: http://www.gumer.info/bibliotek Buks/Culture/Lev-Str/04.php (22.06.2015).

4. Oleg Kuzovkov. Khudozhestvennyi rukovoditel' studii Animakkord. /Portal "Mir 3D", interv'yu s O. Kuzovkovym. Rezhim dostupa: http://www.mir3d.ru/person/586/

5. Propp V. Istoricheskie korni volshebnoi skazki. / Biblioteka Gumer. Rezhim dostupa: http://www.gumer.info/ bibliotek_Buks/Linguist/Propp_2/index.php (Data obrashcheniya: 29.06.2015).

6. Khangil'dieva I.G. Traditsionnye formy $\mathrm{v}$ netraditsionnom kontekste: arenda i koproduktsiya v sfere kul'tury i iskusstva (materialy kursa «Predprinimatel'stvo v kul'ture»).

7. Mart'yanova G.Yu., Il'ina A.A. Potentsial artterapii v sisteme korrektsionnoi pomoshchi doshkol'niku // Psikholog. - 2015. - 1. - C. 94 - 118. DOI: 10.7256/2409-8701.2015.1.13601. URL: http://www.e-notabene.ru/psp/ article_13601.html 